\title{
Recurrent Neisseria infections due to factor D deficiency
}

INSERM

\section{Source}

INSERM. (1999). Orphanet: an online rare disease and orphan drug data base. Recurrent Neisseria infections due to factor D deficiency. ORPHA:169467

Recurrent Neisseria infections due to factor $D$ deficiency is a rare, genetic, primary immunodeficiency disorder characterized by an increased susceptibility to Neisseria bacterial infections, resulting from complement factor $D$ deficiency, typically manifesting as recurrent respiratory infections, recurrent mening itis and/or septicemia. Patients typically present fever, purpuric rash, arthralgia, myalgia and undetectable complement factor D plasma concentrations. 